\title{
Mekanik Özelliklere Göre Ağaç Türlerinin Yapay Sinir Ağları ile Tahmini
}

Predicting wood types in terms of mechanical properties using artificial neural networks

\author{
Muhammer İLKUÇAR ${ }^{1, a}$, Ali İhsan KAYA ${ }^{2, b}$, Ahmet ÇíiFCi*3,c \\ ${ }^{1}$ Mehmet Akif Ersoy Üniversitesi, TBMYO, Bilgisayar Teknolojileri Bölümü, 15100, Burdur \\ ${ }^{2}$ Mehmet Akif Ersoy Üniversitesi, TBMYO, Tasarım Bölümü, 15100, Burdur \\ ${ }^{3}$ Mehmet Akif Ersoy Üniversitesi, Mühendislik-Mimarlık Fakültesi, Elektrik Mühendisliği Bölümü, 15030, Burdur
}

\begin{abstract}
• Geliş tarihi / Received: 04.05.2017 • Düzeltilerek geliş tarihi / Received in revised form: 10.11.2017 • Kabul tarihi / Accepted: 10.11.2017
$\ddot{O} z$

Mekanik özellikler malzemelerin dayanımını ve kullanım alanlarını belirleyen en önemli etkenlerdir. Bir ağaç malzemenin hangi malzeme grubunda olduğu ve hangi ağaç türü olduğu mekanik özelliklerine bakılarak bilinebilmektedir. Bu çalışmada ticareti yapılan kızılağaç (Alnus glutinosa subsp. Barbata), doğu kayını (Fagus orientalis Lipsky), karakavak (Populus nigra), ceviz (Juglans regia), meşe (Quercus robur), kestane (Castena sativa), sedir (Cedrus libani) ve çam (Pinus) gibi önemli bazı ağaç türlerinin mekanik özellikleri yapay sinir ağları ile modellenmiştir. Bu çalışma, herhangi bir konstrüksiyon için ihtiyaç duyulan mekanik özellikleri karşılayacak ideal ağaç malzemenin tespitinde yardımcı olacaktır. Böylece bilimsel çalışmalarda ve ticarette ağaç türü ile ilgili sınıflandırmalar daha etkin bir şekilde yapılabilecektir.
\end{abstract}

Anahtar kelimeler: Ağaç türleri, Mekanik özellikler, Yapay sinir ağları

\begin{abstract}
The mechanical properties are the most important factors determining the strength and usage areas of materials. It can be known from the mechanical properties that a wood material of which material group is in and which wood species it is. In this study, the mechanical properties of some important wood species such as alder (Alnus glutinosa subsp. Barbata), oriental beech (Fagus orientalis Lipsky), black poplar (Populus nigra), walnut (Juglans regia), oak (Quercus robur), chestnut (Castena sativa), cedar (Cedrus libani) and pine (Pinus) were modelled by using artificial neural networks. This study will assist in the determination of ideal wood material that meets the mechanical properties required for any construction. Thus, classifications related to wood species can be made more effectively in scientific studies and in trade.
\end{abstract}

Keywords: Wood species, Mechanical properties, Artificial neural networks

\footnotetext{
*c Ahmet ÇífCi; acifci@ mehmetakif.edu.tr; Tel: (0248) 21327 77; orcid.org/ 0000-0001-7679-9945

${ }^{a}$ orcid.org/ 0000-0002-4935-8148 $\quad$ b orcid.org/ 0000-0002-1860-9610
} 


\section{Giriş}

Doğadan saf biçimde elde edilen ağaç geleneksel bir malzeme olarak; işlenme kolaylığı, direnç özellikleri ve maliyet avantajları nedeniyle yaygın bir kullanım olanağına sahiptir. Ağacın on binlerce farklı kullanım alanı olduğu tahmin edilmektedir. Ağaç malzemenin bu kadar çok kullanım alanının olmasının en büyük nedeni anatomik yapısı, fiziksel ve mekanik özellikleriyle kimyasal bileşiminden kaynaklanmaktadır (Bozkurt ve Erdin, 1997).

Uzun ve mükemmel bir tarihe sahip olan ağaç; insanın yaşamında ve kültürünün gelişme süreci içerisinde yüzlerce yıldır binaların çeşitli kısımlarında taşıyıcı elemanlar, diş cephe kaplamaları, döşeme ve çatı malzemeleri olarak, endüstriyel konstrüksiyonlarda köprüler, traversler, iskelelerde ve daha pek çok alanda kullanılmaktadır (Erdin, 2003). Bunun yanında heterojen yapida olmas1 ve bu nedenle anizotrop davranması en büyük kusuru olarak görülmektedir (Rowell, 1990).

Herhangi bir malzemenin kullanım yeri seçiminde öncelikle mekanik özelliklerin bilinmesi gereklidir. Ağaç malzemenin mekanik özellikleri; ağaç türüne, özgül ağırlığına, anatomik yapısına, kimyasal bileşimine, coğrafi orijinine, yetişme bölgesine, rutubet miktarına, fiziksel yapısına, kuvvetin şiddetine ve etki yönüne bağlidır. $\mathrm{Bu}$ nedenle mekanik özelliklerinin tespit edilmesi diğer malzemelere göre değişken ve farklı olabilmektedir. (Bozkurt ve Erdin, 1997)

Ağaç malzemeyi doğal dayanıklılıklarına göre sınıflandırmak için çeşitli çalışmalar yapılmıştır. Panshin ve De Zeeuw (1980) çalışmalarında Amerikan ağaç türlerini dayanıklı veya çok dayanıklı, orta derece dayanıklı ve az dayanıklı veya dayanıksız olarak sınıflandırmıştır. Berkel (1972) tarafından yapılan çalışmada ağaç türleri dayanma süreleri bakımından çok dayanıklı, orta derece dayanıklı ve az dayanıklı ağaç türleri olarak sınıflandırmıştır. ASTM (American Society for Testing Materials) D2017-81 (1986) standardında denemeler sonucu elde edilen ağırlık kaybına göre yüksek dayanıklı, dayanıklı, orta derece dayanıklı, az dayanıklı veya dayanıksız şeklinde bir sınıflandırma yapılmıştır. Findlay (1985) ise yine dayanıklılık esasına göre ağaç türlerini çok dayanıklı, dayanıklı, orta derece dayanıklı, az dayanıklı ve dayanıksız olarak beş farklı sınıfa ayırmıştır.
Türkiye'de yetişen bazı ağaç türlerinin fizikomekanik değerler esas alınarak sahip oldukları mevcut ya da oluşturulmuş bulunan sınıf gruplarına dağılımı yapılmıştır. Sınıflandırmada genelde belirlenmiş olan fiziksel özelliklerden hava kurusu \% 12-15 yoğunluk, daralma, mekanik özelliklerden eğilme direnci, eğilmede elastikiyet modülü, dinamik eğilme, basınç, çekme, yarılma, makaslama dirençleri ve sertlik değerleri dikkate alınmıştır (As vd., 2016).

Bir ağaç malzemenin mekanik özelliklerine bakarak onun hangi malzeme grubunda olduğu ve hangi ağaç türü olduğunun bilinmesi büyük bir ihtiyaçtır. Özellikle mühendislik tasarım hesaplamalarında teorik olarak, mekanik özelliği belirli güven sınırlarında yerine getirebilecek malzemenin belirlenmesi bu açıdan çok önemlidir. Bununla beraber laboratuvar çalışmalarında mekanik özelliklerinden ağaç türünün belirlenmesi gerekliliği kendini etkin bir şekilde göstermektedir. Mekanik özelliklerine göre ağaç türünün tespit edilmesi ile ilgili bir çalışmaya rastlanmamıştır. Yapılan çalışmada, yapay sinir ağları (YSA) sınıflandırma yöntemleri yardımıyla, mekanik özelliklerine göre ağaç malzemenin türünün tespiti işlemi yapılmıştır.

\section{Yapay Sinir Ağları}

Yapay sinir ağı, bilinen beyin yapısının çalışma prensibi taklit edilerek geliştirilmiş öğrenme/hafiza temelli bir makine öğrenme algoritmasidır. YSA; esnek ve beklenmedik durumlara karşı mantıklı yaklaşımlarından dolayı matematiksel/istatistiksel yöntemlerle çözülebilen problemlerde dahi tercih edilmeye başlanmıştır. Günümüzde YSA; sosyal bilimler, tıp, mühendislik, gibi farklı disiplinlerde sinıflandırma, kümeleme, tahmin, otonom sürüş, doğal dil işleme, örüntü tanıma gibi farklı problemlerin çözümündeki marifeti ile haklı bir şöhrete sahiptir. Dolayısıyla, kullanım alanı, ağ yapıs1 ve öğrenme yöntemleri de geliştirilmektedir. Yapılan çalışmada ağacın mekanik özelliklerine göre ağacın türünün tahmini (sınıflandırması) işlemi çok katmanlı ileri beslemeli eğri yayılımlı ve radyal temelli YSA kullanılarak gerçekleştirilmiştir.

\section{1. Çok Katmanlı İleri Beslemeli Geri Yayılımlı Yapay Sinir A}

YSA beyin öğrenme mantığından esinlenerek geliştirildiğinden, ağ öncelikli bir öğrenme sürecine tabi tutulmalıdır. Bunun için konu ile ilgili yeteri kadar gerçek veri kullanılarak ağın 
öğretilmesi işlemi gerçekleştirilir. Öğrenme süreci statik olduğu gibi, yeni gelişen şartlara göre sürekli öğrenen yani dinamik de olabilir. Ağın öğrenmesi; daha önce hiç görmediği, bilmediği bir veri için dahi bir yorum getirebildiği, uygun çıkışın elde edilebileceği ağırlık değerlerinin hesaplanması sürecidir. Bir YSA öğretmek için farklı ögrenme metotları kullanılabilir (Anthony ve Bartlett, 2009). Literatürde farklı amaçlar için kullanılan farklı türde YSA modelleri mevcuttur. Şekil 1'de çok katmanlı ileri beslemeli-geri yayılımlı (ÇKİBGY) yapay sinir ağı yapısı görülmektedir.

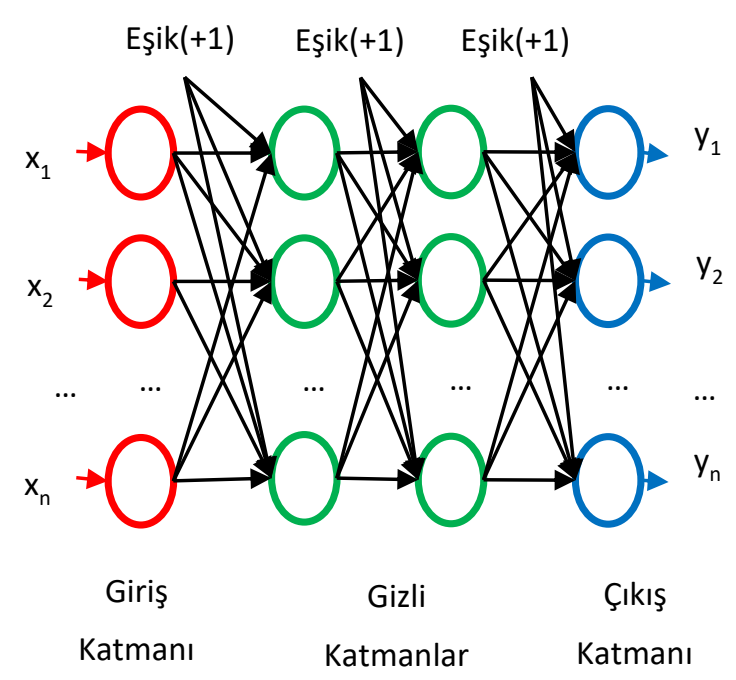

\section{Şekil 1. Çok katmanlı YSA yapısı}

$\mathrm{Bu}$ tür ağlarda bir giriş katmanı, bir çıkış katmanı ve en az bir gizli katman bulunur. Her katmandaki düğümler bir sonraki katmandaki düğümleri besleyecek şekilde birbirine bağlıdır. Giriş katmanı düğüm sayısı problemdeki öz nitelik sayısı ile ilişkilidir. Bir düğüm giriş bilgilerinin sıfır olması durumunda tüm hesaplamaların sifır olmaması için, giriş katmanı hariç tüm katmanlara değeri $(+1)$ olan bir eşik düğüm ilave edilmelidir. Çıkış düğüm sayısı olarak, istenen sonuçları karşılayabilecek kadar düğüm tasarımcı tarafından eklenebilir. Gizli katman sayıs ve her gizli katmandaki düğüm sayısı ile ilgili literatürde bir hesaplama mevcut değildir. Problemin özelliğine göre gizli katman sayısı ve bunların dügüm sayıları değiştirilerek farklı ağ yapıları düzenlenip en iyi sonucu veren YSA ağı, tasarımcı tarafından tespit edilmelidir. Giriş katmanı hariç diğer katmanlardaki dügümler (algılayıcı) kendisine gelen sinyalleri işleyerek bir çıktı üretir. Şekil 2'de YSA'ya ait bir dügüum yapısı verilmiştir.

Bir düğüm, kendisine gelen ağırlık değerleri ve verilerin çarpımlarının toplamını alıp bir net değeri üretir (denklem 1).

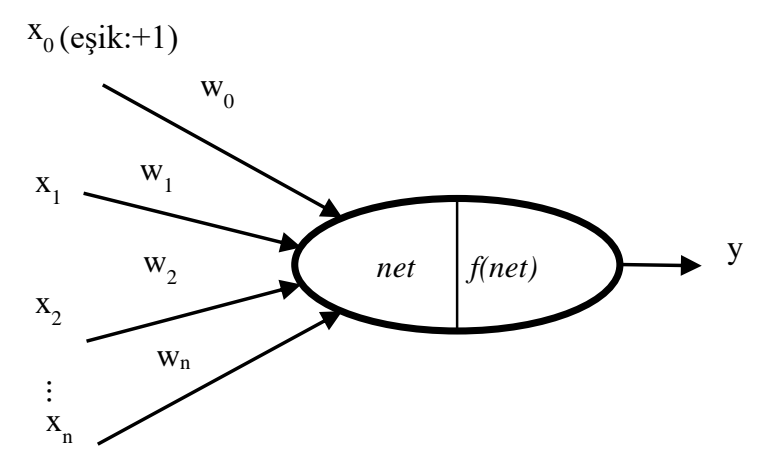

Şekil 2. YSA düğüm yapıs1

$\mathrm{Bu}$ değer bir transfer fonksiyonu yardımıyla $[0,1]$ veya $[-1,1]$ aralığına çekilir. Çok katmanlı YSA geri yayılım hesaplamasında, türevi kolay alınmasından ve sürekli olmasından dolayı, işlem kolaylığ 1 sağlayan sigmoid transfer fonksiyonu (şekil 3) tercih edilir (denklem 2). Literatürde sinüs, hiperbolik tanjant, lineer, step vb. farkl1 transfer fonksiyonları kullanılmaktadır.

$$
\begin{aligned}
& n e t=\mathrm{w}_{0}+\sum_{k=1}^{n}\left(\mathrm{x}_{i} \mathrm{w}_{i}\right) \\
& f(n e t)=\frac{1}{(1+e)^{-n e t}}
\end{aligned}
$$

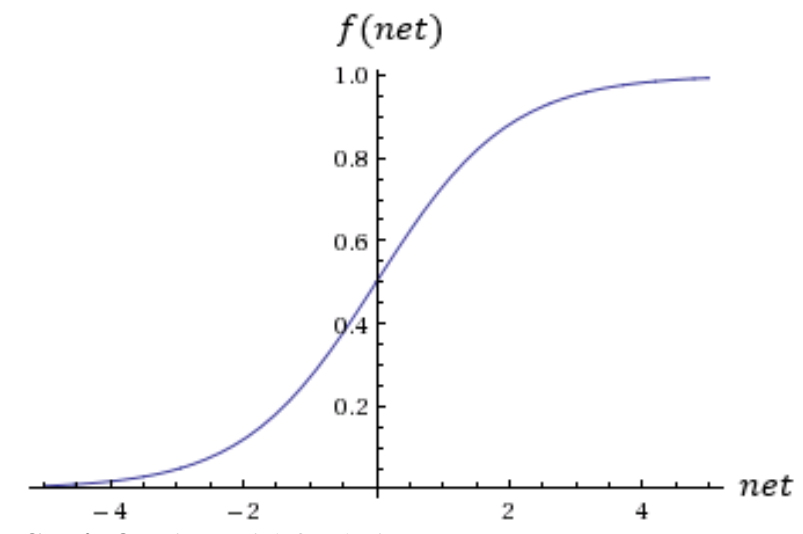

Şekil 3. Sigmoid fonksiyonu

YSA'lar öğrenme şekillerine göre genel olarak gözetimli (Supervised Learning), gözetimsiz (Unsupervised Learning) ve pekiştirmeli öğrenme (Reinforcement Learning) olarak gruplandırılabilir.

Çalışmada sınıflandırma işlemi yapıldığından gözetimli öğrenme YSA kullanılmıştır. $\mathrm{Bu}$ tür öğrenme işlemi; ağ ileri doğru beslendikten sonra hata değerleri (ağdan elde edilen çıkış ile beklenen çıkış değeri arasındaki fark Hata= beklenen_değer - gerçekleşen_değer), geriye doğru yansitılarak, hatay1 minimum edecek şekilde ağırlık değerlerinin değiştirilmesi 
işlemidir. Başka bir deyişle ağın öğrenmesi işlemi, hatayı minimum edecek ağırlık değerlerinin belirlenmesi sürecidir. $\mathrm{Bu}$ işlem için farklı optimizasyon teknikleri kullanılabilir. Ağın hata değerini minimum yapmak için, dereceli azalma (Gradient Descent) yöntemi yaygın olarak kullanılmaktadır. Bu prensibe göre, çıkıştan girişe doğru zincirleme olarak dügümlerin çıkış fonksiyonu (transfer fonksiyonu) türevleri ağırlıklara yansitılarak öğrenme işlemi gerçekleştirilir (denklem 3, 4, 5). Denklem 4'te $\delta_{k}$ değeri hata fonksiyonu türevidir. Geriye doğru yayılımda, bir dügümün toplam hata miktarı değeri ona gelen hata miktarlarının ağırlıkları ile çarpımı toplamı kadar olacaktır. Denklem 5'de hata miktarları dikkate alınarak ağırlık değişimi yapılmıştır.

$\frac{\partial E}{\partial w_{i}}=\frac{\partial}{\partial y_{i}} \frac{\partial y_{i}}{\partial r_{i}} \frac{\partial r_{i}}{\partial w_{i}}$

$\delta_{k}=\sum_{k=0}^{K} \delta_{y} * \mathrm{w}_{k, z}$

$\mathrm{W}_{i, k}=\mathrm{W}_{i, k}+\delta_{y} \mathrm{x}_{i} \mathrm{f}\left(\text { net }_{\mathrm{k}}\right)^{\prime}$

Ağın eğitimi ve test süreçlerinde bazı performans kriterlerine göre karar verilir. Performans kriterleri olarak ağın hata değerlerine bakılır. Çalışmada hataların mutlak değerlerinin toplamının ortalaması (Mean Absolte ErrorMAE) kullanılmıştır (Denklem-6).

$M A E=\frac{1}{n} \sum_{i=0}^{n}\left|z_{i}-y_{i}\right|$

Eğitilmiş YSA test verileri ile çalıştırılıp doğru ve yanlış tahmin oranlarına bakılarak performans (regresyon) ölçüsü olarak değerlendirilebilir.

\section{Levenberg-Marquardt Algoritmast}

Levenberg-Marquardt algoritması (LMA) GaussNewton metodunu ve Steepest Descent metodunu birleştiren yinelemeli bir yöntemdir. GaussNewton algoritmasinın hız avantajını, Steepest Descent metodunun da kararlılığını almıştır. Gauss-Newton algoritmasından daha güçlüdür, çünkü çoğu durumda hata yüzeyi kuadratik durumdan çok daha karmaşık olsa bile iyi bir şekilde yakınsayabilir. LMA, Gauss-Newton algoritmasına göre biraz daha yavaş olma eğiliminde olmasına rağmen (yakınsak durumda), Steepest Descent metodundan çok daha hızlı yakınsar (Yu ve Wilamowski, 2011). LMA şu şekilde verilebilir (Wen vd., 2011):

$\Delta x=-\left(J^{T}(x) J(x)+\mu I\right)^{-1} J(x) e(x)$
Burada x ağırlık vektörü, $\mu$ 0'dan büyük bir sabit ve e hata vektörüdür. $P$ eğitim örnek sayısını ve $N$ değişken sayısını belirtmek üzere $\mathrm{J},(\mathrm{Px} 1) \mathrm{xN}$ boyutunda Jacobiyen matrisi göstermektedir. I birim matristir. Denklem 7'deki $\mu$ önemli bir sabittir. $\mu$ değeri artarsa LMA, Steepest Descent metodu gibi, $\mu$ değeri 0 'a doğru azaldığında Gauss-Newton metodu gibi davranır.

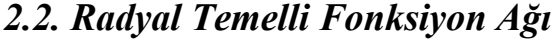

Radyal temelli fonksiyon ağı (Radial Basis Function Network-RBFN) ilk defa Broomhead ve Lowe (1988) tarafindan bazı problemlerin çözümünde başarılı bir şekilde kullanılmıştır. RBFN bir giriş katmanı, bir gizli katman ve bir çıkış katmanından oluşan üç katmanlı bir yapıya sahiptir (Şekil 4).

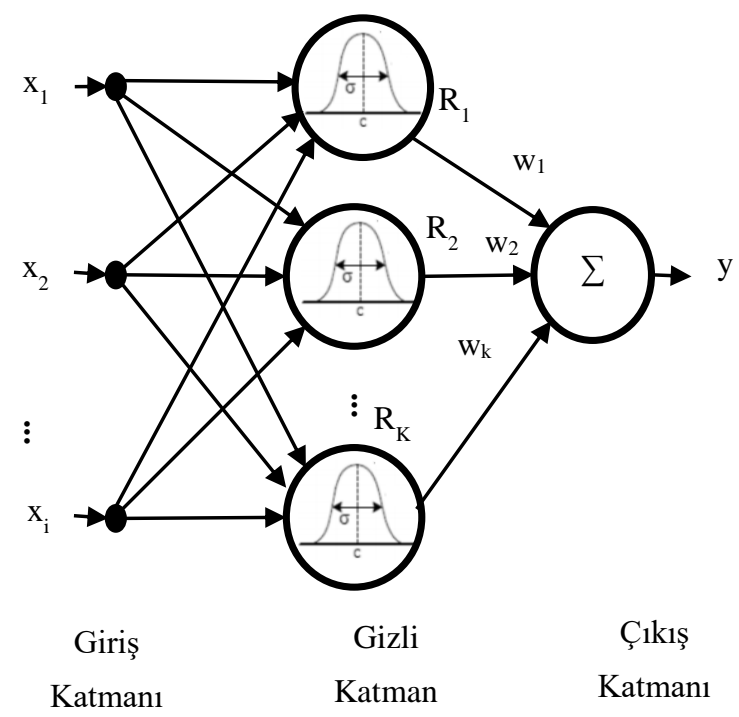

Şekil 4. K adet gizli katmandan oluşmuş bir RBFN yapay sinir ağ1 yapısı (Arisariyawong ve Charoenseang, 2002).

$\mathrm{Bu}$ tür ağlarda tüm katmanlardaki dügümler birbirine bağlıdır. Giriş ve çıkış düğüm sayısı probleme göre belirlenir. Gizli katman dügüm sayıs ise problemin performansina direkt etki eder ve en çok eğitim verisi sayısı kadar olabilir. Gizli katman düğüm sayısı, problemin eğitimi sırasında belirli sayıdan başlatılıp dinamik olarak belirli miktarlarda arttırılarak ağın eğitimi gerçekleştirilir. Giriş katmanı ile gizli katman arasında ağırlık değerleri yoktur. Ağırlık değerleri sadece gizli katman ile çıkış katmanı arasındadır. Gizli katman transfer fonksiyonu olarak literatürde farklı dağılım fonksiyonları (quadratik, invers quadratik vb.) kullanılmasına rağmen en popüler olanı gaussian radyal fonksiyondur. 
Gizli katman çıkış değerleri denklem 8'deki radyal fonksiyon tarafından üretilir. Denklemde, $x$ : veri, $c_{i}$ : giriş veri seti ortalaması (centralitymerkezi), $\sigma_{i}: i$. nitelik verilerinin standart sapmas1 olarak verilmiştir.

$\mathrm{R}_{\mathrm{i}}(x)=\mathrm{e}^{\left(-\frac{\left\|\mathrm{x}-\mathrm{C}_{\mathrm{i}}\right\|^{2}}{2 \sigma_{i}^{2}}\right)}$

RBFN çıkış değeri olarak gizli katman radyal fonksiyon çıkış değeri $\left(\mathrm{R}_{\mathrm{i}}(x)\right)$ ile gizli katmançıkış katmanı ağırlı değerlerinin $\left(\mathrm{w}_{\mathrm{i}}\right)$ çarpımlarının toplamı şeklindedir (denklem 9). Nihai çıkış değeri çıkış düğüm değerlerinin aritmetik ortalaması alınarak bulunur (denklem 10).

$$
\begin{aligned}
& \mathrm{y}_{\mathrm{i}}(\mathrm{x})=\sum_{\mathrm{i}=1}^{\mathrm{K}} \mathrm{w}_{\mathrm{i}} \mathrm{R}_{\mathrm{i}}(x) \\
& \mathrm{y}_{\mathrm{i}}(\mathrm{x})=\frac{\sum_{\mathrm{i}=1}^{\mathrm{n}} \mathrm{w}_{\mathrm{i}} \mathrm{R}_{\mathrm{i}}(x)}{\sum_{\mathrm{i}=1}^{\mathrm{n}} \mathrm{R}_{\mathrm{i}}(x)}
\end{aligned}
$$

RBFN'de parametre ve hesaplamalar az olduğundan hesaplama süresi de kisa olur. RBFN fazla kaynak (işlemci, ram) kullanmadığından kaynakların kisitlı olduğu yerlerde tercih edilebilir. RBFN iyi bir genelleme olanağı, daha az düğüm kullanma ve kısa hesaplama olanağ 1 sunar (Moradkhani vd., 2004).

\section{Ağaç Türlerinin Mekanik Özelliklere Göre Sinıflandırılması}

Ağaçların farklı ortamlarda farklı etkilere karşı gösterdiği tepkiler onun mekanik özelliklerini oluşturur. Mekanik özellikleri doğası gereği az da olsa birbirinden farklıklar gösterir. Dolayısıyla mekanik özelliklerinden yola çıkılarak ağacın türü tahmin edilebilir. Çalışmada kızılağaç (Alnus glutinosa subsp. Barbata), doğu kayını (Fagus orientalis Lipsky), karakavak (Populus nigra), ceviz (Juglans regia), meşe (Quercus robur), kestane (Castena sativa), sedir (Cedrus libani) ve çam (Pinus) gibi sekiz farklı ağaç türüne ait yedi mekanik özellik değerine göre, farklı YSA sınıflandırma metotları (RBFN, ÇKİGG) kullanılarak ağacın türü tahmin edilmiştir.
Her malzemenin aynı koşullar altında yoğunluğu, genleşmesi, burkulması ve büzülmesi farklıdır. Dolayısıyla basınca, itmeye, çekmeye ve burkmaya karşı dirençleri de farklılıklar göstermektedir. $\mathrm{Bu}$ gibi etkilere karşı verilen tepkiler malzemenin mekanik özelliklerini oluşturur. Mekanik özellikler, malzemelerin kullanım yerleri ile ilgili karar vermede büyük paya sahiptirler.

Tüm malzemeler gibi ağaç malzemeleri kullanırken, kullanım yeri ve koşulları için mekanik özellikleri dikkate alınmalıdır. Tablo 1 'de ağaçların bazı mekanik özelliklerini belirleme fonksiyonları verilmiştir. Belirli koşullar altında ağacın yoğunluğu, basınca karşı direnci, eğilme direnci, çekme direnci, burkulma direnci gibi özellik ölçümleri yapılarak ağacın mekanik özellikleri elde edilmiştir.

Tablo 1. Ağaç malzemenin mekanik özellikleri

\begin{tabular}{l}
\hline \multicolumn{1}{c}{ Mekanik Özellikler } \\
\hline Yoğunluk (Tam Kuru) \\
Liflere Paralel Basınç Direnci \\
Eğilme Direnci \\
Eğilme Elastikiyet Modülü \\
Dinamik Eğilme Direnci \\
Makaslama Direnci \\
Liflere Paralel Çekme Direnci \\
\hline
\end{tabular}

Çalışmada kullanılan mekanik özellik verileri çeşitli kaynaklardan elde edilmiştir (Güller ve Ay, 2001; Kantay vd., 2000; Bal vd., 2012; Kaymakç1 vd., 2011; Korkut ve Bektaş, 2008; Düzkale vd., 2015; Malkoçoğlu,1994; Güller vd., 2011; Ay ve Şahin, 2002; Dündar, 2002; Kahveci, 2012). Daha farklı ağaç malzemelerin mekanik özelliklerinin ölçülmesi işlemi için ayrı bir laboratuvar çalışması gerekmektedir. Çalışmada, sekiz farklı ağaç türüne ait yedi farklı mekanik öznitelik olan 180 veri kullanılmıştır. Bunlardan bazılarının mekanik özellikleri Tablo 2' de verilmiştir. Verilerin tümü sayısal veri türünden olup eksik veri bulunmamaktadır. Çalışmada kullanılan verilerin tamamına İlkuçar (2017) kaynağından ulaşılabilir.

\begin{tabular}{|c|c|c|c|c|c|c|c|}
\hline $\begin{array}{l}\text { Ağaç } \\
\text { Türü }\end{array}$ & $\begin{array}{c}\text { Yoğunluk } \\
\text { (Tam Kuru) }\end{array}$ & $\begin{array}{l}\text { Liflere Paralel } \\
\text { Basınç Direnci }\end{array}$ & $\begin{array}{l}\text { Eğilme } \\
\text { Direnci }\end{array}$ & $\begin{array}{c}\text { Eğilme Elastikiyet } \\
\text { Modülü }\end{array}$ & $\begin{array}{c}\text { Dinamik Eğilme } \\
\text { Direnci }\end{array}$ & $\begin{array}{l}\text { Makaslama } \\
\text { Direnci }\end{array}$ & $\begin{array}{l}\text { Liflere Paralel } \\
\text { Çekme Direnci }\end{array}$ \\
\hline Kızılağaç & 0,454 & 42,3 & 79,05 & 8781,6 & 0,58 & 6,276 & 76,3065 \\
\hline Doğu Kayını & 0,59 & 61,74 & 122 & 12050 & 1,09 & 9,9 & 131,6 \\
\hline Kara Kavak & 0,375 & 35 & 50,25 & 8630 & 0,247 & 5 & 77 \\
\hline Ceviz & 0,62 & 56 & 121 & 10259,7 & 0,95 & 9,6 & 101 \\
\hline Meşe & 0,64 & 58,2 & 117,5 & 12161 & 0,6 & 10,2 & 90 \\
\hline Kestane & 0,59 & 56,96 & 77 & 9050 & 0,59 & 9,7 & 137 \\
\hline Sedir & 0,524 & 44,6 & 75,8 & 6668,2 & 0,38 & 5,2 & 101 \\
\hline Çam & 0,56 & 55 & 109 & 10200 & 1,68 & 9,8 & 112 \\
\hline
\end{tabular}

Tablo 2. Bazı ağaç türleri ve mekanik özellikleri 
Şekil 5’te sistemin YSA ağ yapısı görülmektedir.

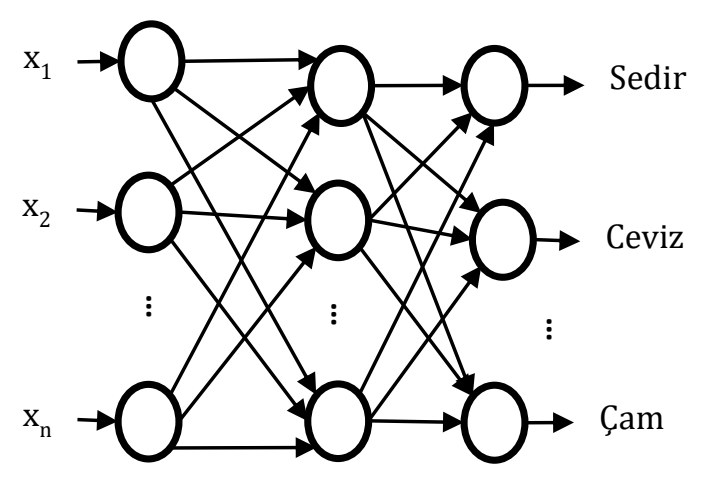

Şekil 5. Ağaçların teknik özelliklerine göre türünün YSA ile tahmini işleminin ağ yapısı

Problemde yedi öznitelik olduğundan ağın giriş düğüm sayısı yedi adettir. Çıkış düğüm sayısı da sınıflandırması yapılacak ağaç türü kadardır. Çalışmada gizli katman olarak tek katman kullanılmıştır. Gizli katman düğüm sayları değiştirilerek farklı ağ mimarileri elde edilerek eğitim yapılmış ve performans değerleri karşılaş̧ırılarak ideal ağ yapisı bulunmaya çalışılmıştır.

Tablo 3'te ÇKİBGY yapay sinir ağ 7 giriş, 8 çıkış katmanı ve farklı gizli katman mimarileri ile eğitilmiş ve ağın test verisine karşı doğru tahmin oranı ile hata miktarı gösterilmiştir. YSA parametreleri olarak; en iyi performans değerini veren (Tablo 4) 0.5 öğrenme katsayısı, 0.5 momentum değeri, sigmoid transfer fonksiyonu ve hataların mutlak değerlerinin toplamının ortalamas1 (Mean Absolte Error- MAE) performans ölçeği kullanılmıştır. Verilerin \%70'i eğitim, kalan \%30'da test için kullanılmıştır. Eğitim ve test verileri 180 veri içerisinden rastgele seçilmiştir.

Performans değeri; eğitilmiş ağın; test verisinden ne kadarını doğru tahmin ettiğini gösterir ve (Doğru Tahmin Sayısı / Test Veri Saylsı *100) şeklinde hesaplanır.

Tablo 3'te görüldüğü gibi gizli katman düğüm sayısı 4'ten başlatılıp (giriş veri nitelik sayısının yarıs1) 30'a kadar ikişer arttırılarak test edilmiştir. Tabloda görüldüğü gibi ağ mimarisi ile performans değeri arasında, belirli bir ilişki görülmemektedir. \%96.29 doğruluk oranına sahip iki YSA mimarisi (7-16-8 ve 7-26-8) en iyi performans değerine sahiptir. Burada 7 giriş katmanı dügüm sayısını, 16 veya 26 gizli katman düğüm sayısını ve 8 'de çıkış katmanı dügüum sayısını belirtmektedir.
Tablo 3. ÇKİBGY yapay sinir ağı 7 giriş, 8 çıkış katmanı ve farklı gizli katman mimarileri ile eğitilmiş ve ağın test verisine karşı doğru tahmin oranı ile hata miktarı

\begin{tabular}{ccc}
\hline $\begin{array}{c}\text { Gizli Katman } \\
\text { Düğ̈̈m Sayısı }\end{array}$ & Performans & $\begin{array}{c}\text { Hata } \\
\text { Miktarı }\end{array}$ \\
\hline 4 & $\% 85.18$ & 0.0502 \\
6 & $\% 90.74$ & 0.0349 \\
8 & $\% 88.88$ & 0.0316 \\
10 & $\% 90.74$ & 0.0255 \\
12 & $\% 92.59$ & 0.0286 \\
14 & $\% 90.74$ & 0.0281 \\
$\mathbf{1 6}$ & $\mathbf{\% 9 6 . 2 9}$ & $\mathbf{0 . 0 1 9 3}$ \\
18 & $\% 90.74$ & 0.0282 \\
20 & $\% 92.59$ & 0.0250 \\
22 & $\% 92.29$ & 0.0298 \\
24 & $\% 94.44$ & 0.0235 \\
$\mathbf{2 6}$ & $\mathbf{\% 9 6 . 2 9}$ & $\mathbf{0 . 0 1 8 3}$ \\
28 & $\% 90.74$ & 0.0275 \\
30 & $\% 94.44$ & 0.0212 \\
\hline
\end{tabular}

Aynı performansa sahip ağlardan, daha az gizli katman sayısına sahip olan ağ, daha az hesaplama gerektirdiğinden tercih edilmelidir. Öte yandan hata oranları da önemlidir. Daha düşük hata oranına sahip YSA ağı tercih sebebi olmalıdır. Bu durumda Tablo 3'e göre en iyi performans ve en düşük hata oranı değerine sahip olan 7-16-8 ağ mimarisi en uygun çok katmanlı ileri beslemeli geri yayılımlı YSA olacaktır.

En iyi performansa sahip ă mimarisi (7-16-8) farklı YSA parametreleri (öğrenme, momentum) ile testler yapılmış ve elde edilen sonuçlar Tablo 4'te gösterilmiştir. Çalışmada kullanılan veri için momentum değerinin ve öğrenme katsayısının performans1 çok az etkilediği görülmektedir. En iyi performans öğrenme oran 0.5 ve momentum 0.5 değeri için elde edilmiştir.

Tablo 4. ÇKİBGY yapay sinir ağ $7-16-8$ mimarisi için farklı ögrenme oranı ve momentum değerleri için performans ve hata oranları

\begin{tabular}{cccc}
\hline Momentum & $\begin{array}{c}\text { Öğrenme } \\
\text { oranı }\end{array}$ & Performans & $\begin{array}{c}\text { Hata } \\
\text { Miktarı }\end{array}$ \\
\hline & 0.1 & $\% 94.44$ & 0.0263 \\
& 0.2 & $\% 96.29$ & 0.0218 \\
0.5 & 0.3 & $\% 96.29$ & 0.0196 \\
& 0.6 & $\% 96.29$ & 0.0175 \\
& 0.8 & $\% 96.29$ & 0.0195 \\
\hline 0.1 & & $\% 96.29$ & 0.0202 \\
0.3 & 0.5 & $\% 96.29$ & 0.0190 \\
0.5 & & $\mathbf{\% 9 6 . 2 9}$ & $\mathbf{0 . 0 1 7 3}$ \\
0.8 & & $\% 96.44$ & 0.0210 \\
\hline
\end{tabular}


Çok katmanlı YSA da en iyi ağ yapısına ait test verisi karışıklık matrisine (confusion matrix) göre farklı ağaç türlerine ait 54 test verisinden 8 kızılağaç verisinden 2 tanesi sedir olarak yanlış tahmin edilmiş, diğer ağaç türlerinin tümü doğru tahmin edilmiştir (Tablo 5).

Tablo 5. Karışıklık matrisi

\begin{tabular}{|c|}
\hline a b c d e f g h | Ağaç türleri \\
\hline 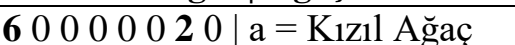 \\
\hline 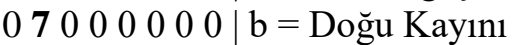 \\
\hline \begin{tabular}{lllllll|c}
0 & 3 & 0 & 0 & 0 & 0 & 0 & $\mid c$
\end{tabular}$=$ Kara Kavak \\
\hline 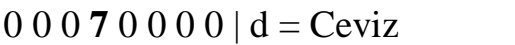 \\
\hline $\begin{array}{lllllllll}0 & 0 & 0 & 6 & 0 & 0 & 0 & \mathrm{e}=\text { Meşe }\end{array}$ \\
\hline $\begin{array}{llllllll}0 & 0 & 0 & 0 & 8 & 0 & 0 & 0\end{array} \mid \mathrm{f}=$ Kestane \\
\hline \begin{tabular}{llllllll|}
0 & 0 & 0 & 0 & 0 & 8 & 0 & $\mathrm{~g}$
\end{tabular}$=$ Sedir \\
\hline $\begin{array}{llllllll}0 & 0 & 0 & 0 & 0 & 0 & 0 & 7\end{array} \mathrm{~h}=$ Çam \\
\hline
\end{tabular}

Çalışmada çok katmanlı ileri beslemeli geri yay1lımlı YSA ile birlikte RBFN YSA ile de veriler test edilmiş ve her iki YSA'ya ait sınıflandırma performans sonuçları Tablo 6'da verilmiştir. Tablodan da görüldüğü gibi RBFN'de \%92.59 doğruluk oranı gibi iyi bir performans göstermiştir. RBFN ağlar daha az hesaplama gerektirdiğinden, düşük maliyetli cihazlar olan mikro denetleyici gibi düşük saat hızı ve belleğe sahip aygitlarda tercih edilebilir.

Tablo 6. Farklı YSA yöntemlerine göre sınıflandirma performans sonuçları

\begin{tabular}{ccc}
\hline $\begin{array}{c}\text { YSA } \\
\text { Yöntemi }\end{array}$ & $\begin{array}{c}\text { Doğru Tahmin } \\
\text { Oranı }\end{array}$ & $\begin{array}{c}\text { Hata } \\
\text { Miktarı }\end{array}$ \\
\hline RBFN & $\% 92.59$ & 0.0185 \\
ÇKIBBGY & $\% 96.29$ & 0.0173 \\
\hline
\end{tabular}

Şekil 6'da ÇKİGY ağın 7-16-8 mimarisi eğitim sırasında yinelemelere göre hata miktarı değişim grafiği verilmiştir. Grafikte görüldüğü gibi yinelemeler ilerledikçe hata miktarı azalmaktadır. 1000 yinelemeden sonra hata miktarı sabit kalmaktadır, burada eğitim işılemi durdurulmuştur. Eğitime devam etmek çözümü kötüleştirebilir.

RBF ağı eğitimi gizli katman düğüm sayısı değiştirilerek yapılmaktadır. Gizli katman düğüm sayısındaki belirli bir değerden sonra hata oranında dramatik bir değişim yaşanmaktadır. $\mathrm{Bu}$ yüzden hata değişim grafiğ SSekil 7 (a) ve Şekil 7 (b) şeklinde iki bölüm halinde verilmiştir. RBFN gizli katman sayıs 120' den itibaren hata miktarında hızlı bir düşüş görünmekte ve bu sayı 130'a ulaştığında en düşük hata seviyesine ulaşmaktadır. En iyi performans için ağın gizli katman sayısı bu seviyede tutulmalıdır.

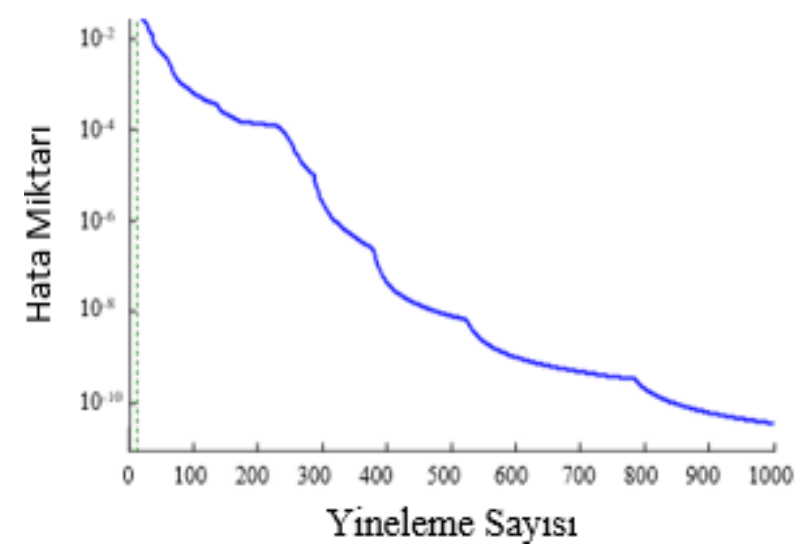

Şekil 6. ÇKİBGY ağın eğitim hata miktarı

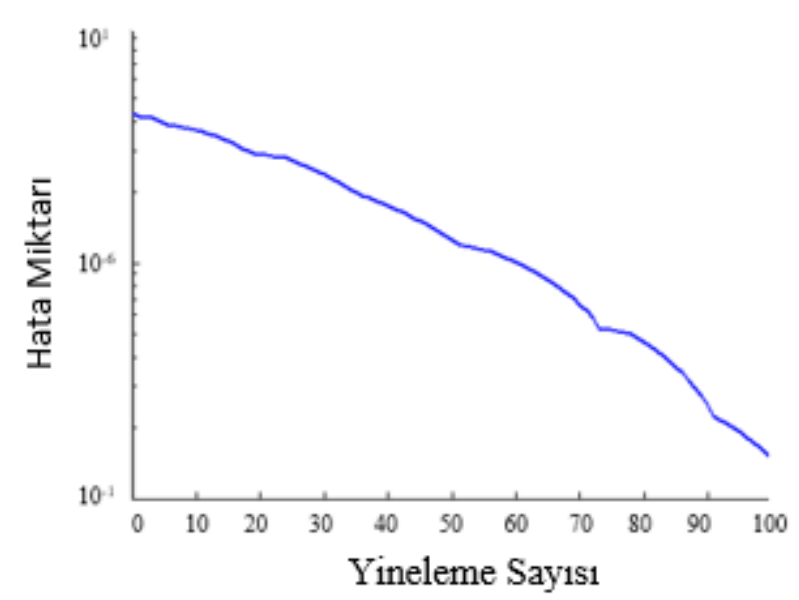

(a)

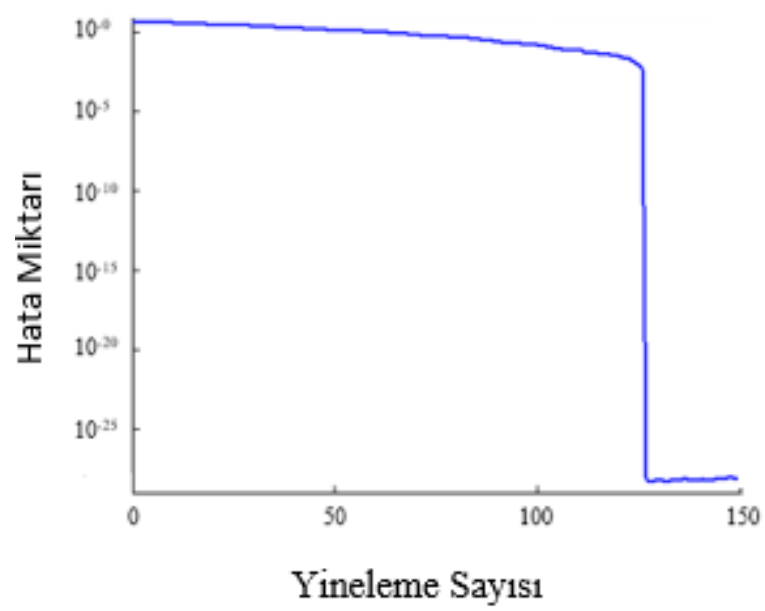

(b)

Şekil 7. (a) İlk 100 yineleme için RBF ağın eğitim hata miktarı değişim grafiği (b) Tüm yinelemeler için RBF ağın eğitim hata miktarı değişim grafiği.

\section{Sonuç ve Öneriler}

Çalışmada sekiz farklı ağaç türüne ait yedi farklı mekanik özelliğe sahip 180 veri farklı tip (ÇKİBGY, RBFN) ve mimaride YSA kullanılarak ilk defa mekanik özelliklerinden ağacın türünün tahmini işlemi yapılmıştır. 
Performans sonuçları açısından çok katmanlı ileri beslemeli geri yayılımlı YSA \%96.29 doğruluk oranında tahmin yaparken, RBFN YSA \%92.59 oranında tahminde bulunmuştur. RBFN ile ÇKİBGY arasında \%3.7'lik bir performans fark1 gözükmektedir. Ancak RBFN YSA daha az parametre ve hesaplamaya sahip olduğundan daha kısa sürede öğrenmekte ve daha hızlı hesaplama yapabilmektedir. Dolayısıyla tahmin işlemini mikro denetleyici gibi düşük kapasiteli $(\mathrm{MHz}$ seviyesinde frekanslarla çalışan ve sınırlı hafızası olan) cihazlarda yapılabilmesi için tercih sebebi olabilir.

Çalışma, herhangi bir konstrüksiyon için ihtiyaç duyulan mekanik özellikleri karşılayacak ideal ağaç malzemenin tespitinde yardımc1 olacaktır. Böylece belirli güven aralığında malzeme ile ilgili yanılma payı minimize edilecektir.

Çalışma ve elde edilen sonuçlar, ağaç malzemenin teknik özelliklerini bulup buna göre ağacin türünü tespit edebilen mikro denetleyici kontrollü elektro-mekanik bir cihaz üretilmesinde yardımcı olacaktır.

\section{Kaynaklar}

Arisariyawong, S. ve Charoenseang, S., 2002, Dynamic Self-Organized Learning for Optimizing the Complexity Growth of Radial Basis Function Neural Networks, IEEE International Conference on Industrial Technology, 11-14 Dec. 2002, Bankok, Thailand, p. 655-660.

As, N., Dündar, T. ve Büyüksarı, Ü., 2016. Classification of wood species grown in Turkey according to some physicomechanic properties, Journal of the Faculty of Forestry Istanbul University, 66, 2, 727735.

ASTM D2017-81, 1986. Accelerated Laboratory Test of Natural Decay Resistance of Woods.

Ay, N., \& Şahin, H. (2002). Maçka-Çatak Bölgesi Anadolu Kestanesi (Castanea Sativa Mill.) Odununun Bazi Mekanik Özellikleri. Artvin Çoruh Üniversitesi Orman Fakültesi Dergisi, 3(1), 87-95.

Bal B. C., Bektaş İ. ve Kaymakçı A., 2012. Toros sedirinde genç odun ve olgun odunun bazı fiziksel ve mekanik özellikleri, Kahramanmaraș Sutcu Imam University Journal of Engineering Sciences, 15, 2, 17 27.
Berkel A., 1972, Ağaç Malzeme Teknolojisi, Ağaç Malzemenin Korunması ve Emprenye Tekniği, İ.Ü. Orman Fakültesi, Yayın No: 1745/183, Sermet Matbaas1, İstanbul.

Bozkurt, A. Y., ve Erdin, N., 1997, Ağaç Teknolojisi, Yayın No: 3998, ISBN 975404-449-X, İstanbul, s. 346-357.

Broomhead D. S. ve Lowe D., 1988. Multivariable functional interpolation and adaptive network, Complex Systems, 2, 321-355.

Dündar, T. (2002). Demirköy yöresi istranca meşelerinin (Quercus hartwissiana stev.) mekanik özellikleri. Journal of the Faculty of Forestry Istanbul University| İstanbul Üniversitesi Orman Fakültesi Dergisi, 52(2), 159-176.

Düzkale, G., Bektaş, İ., Tunç, H. H. ve Doğanlar, Y., 2015. Zeytin ağac1 (Olea europaea) odunun bazı fiziksel ve mekanik özelliklerinin belirlenmesi, Düzce Üniversitesi Ormanc1lık Dergisi, $10, \overline{2,29-}$ 35.

Erdin, N., 2003, Ağaç Malzeme Kullanımı ve Çevreye Etkisi, İnterteks İnşaat 2003 Fuarı, Ahşap Seminerleri, 20-22 Şubat, İstanbul.

Findlay, W. P. K., 1985, Preservation of Timber in the Tropics, Martinus Nijhoof/DR W. Junk Publishers, ISBN 90-247-3112-7, Dordrecht, Netherlands.

Güller B. ve Ay N., 2001. Artvin yöresi sakallı kızılağaç (Alnus glutinosa subsp. barbata (C. A. Mey.) Yalt.) odununun bazı mekanik özellikleri, Turkish Journal of Agriculture and Forestry, 25, 2, 129-138.

Güller, B., Isik, K. ve Cetinay, S. (2011). Genetic variation in Pinus brutia Ten.: Wood density traits. BioResources, 6(4), 4012-4027.

İlkuçar, (2017). http://www.ilkucar.com/data/ agacmek.xlsx (Erişim tarihi:25.08.2017)

Kahveci, E. (2012). Farklı Yetişme Ortamı Koşullarının Sakallı Kızılağaç (Alnus glutinosa subsp. barbata (CA Mey.) Yalt.) Odununun Bazı Fiziksel ve Mekanik Özelliklerine Etkileri. Yüksek Lisans Tezi, Karadeniz Teknik Üniversitesi, Trabzon.

Kantay, R., As, N. ve Ünsal, Ö., 2000. The mechanical properties of walnut (Juglans 
regiaL.) wood, Turkish Journal of Agriculture and Forestry, 24, 6, 751-756.

Kaymakc1, A., Bal, B. C. ve Bektaş, İ., 2011. Pavlonya odununun bazı özellikleri ve kullanım alanları, Kastamonu Üniversitesi Orman Fakültesi Dergisi, 11, 2, 228-238.

Korkut, S., ve Bektas, I., 2008. The effects of heat treatment on physical properties of Uludag fir (Abies bornmuelleriana Mattf.) and Scots pine (Pinus sylvestris L.) wood, Forest Products Journal, 58, 3, 95-99.

Malkoçoğlu, A. K. (1994). Doğu Kayını (Fagus orientalis Lipsiky) Odununun Teknolojik Özellikleri, Doktora Tezi, KT Ü. Orman Fakültesi, Trabzon.

McCulloch W. S. ve Pitts W., 1943. A logical calculus of the ideas immanent in nervous activity, Bulletin of Mathematical Biophysics, 5, 115-133.

Moradkhani H., Hsu K., Gupta H. V. ve Sorooshian S., 2004. Improved streamflow forecasting using self-organizing radial basis function artificial neural networks, Journal of Hydrology, 295, Issues 1-4, 246-262.

Panshin, A. J. ve De Zeeuw, C., 1980, Textbook of Wood Technology, Mc Graw-Hill, Inc. Fourth Edition, ISBN: 0-07-04844-4, New York.

Rowell, R. M., 1990, Materials Science of Lignocellulosics, Materials Research Society Symposium Proceedings, 197, Pittsburgh, PA, p. 3-9.

Wen, L., Li, Z., Han, Z., Xie, X., Zhang, R., 2016, The External Characteristics Simulation System of Diesel Engine Based on Levenberg-Marquardt Algorithm, IEEE International Conference on Industrial Informatics - Computing Technology, Intelligent Technology, Industrial Information Integration (ICIICII), 3-4 Dec. 2016, Wuhan, China, p. 30-33.

Yu, H. ve Wilamowski, B. M., 2011, LevenbergMarquardt training. Industrial Electronics Handbook Intelligent Systems. Wilamowski, B. M. and Irwin, J. D. (eds.), CRC Press, Boca Raton. pp. 1-16. 